\title{
PENGEMBANGAN MODUL GEOMETRI BERBASIS RECIPROCAL TEACHING UNTUK MENINGKATKAN KEMAMPUAN KOMUNIKASI MATEMATIS MAHASISWA CALON GURU
}

\author{
Kenys Fadhilah Zamzam \\ IKIP Budi Utomo Malang, Jl. Simpang Arjuna 14B, Malang, Jawa Timur, Indonesia \\ kenysfz@gmail.com
}

\begin{abstract}
The purpose of this study is to produce a geometry module based on reciprocal teaching to improve mathematical communication skills of prospective teacher students. The development phase-development module uses the Plomp development model. The module validation results obtained an overall average of 3.4 while the modules developed fall into the valid category or are suitable for use. The average practicality result of 3.0 which is included in the practical category is used. The results obtained from mathematical communication solutions of prospective teacher students increased by 0.52 while included in the medium category and the average results of student responses amounted to 2.52 which showed students gave positive responses to the reciprocal teachingbased geometry module. Thus, the overall module is based on reciprocal teaching that is able to improve the communication skills of prospective teacher students.
\end{abstract}

Keywords: Modules, Reciprocal teaching, Mathematical communication

\begin{abstract}
Abstrak
Tujuan penelitian ini adalah menghasilkan modul geometri berbasis reciprocal teaching untuk meningkatkan kemampuan komunikasi matematis mahasiswa calon guru. Tahap-tahap pengembangan modul menggunakan model pengembangan Plomp. Hasil validasi modul diperoleh rata-rata secara keseluruhan sebesar 3,4 dimana modul yang dikembangkan masuk dalam kategori valid atau layak digunakan. Hasil rata-rata praktikalitas sebesar 3,0 dimana masuk dalam kategori praktis digunakan. Hasil efektivitas dinilai dari kemampuan komunikasi matematis mahasiswa calon guru yaitu meningkat sebesar 0,52 dimana masuk dalam kategori sedang dan hasil rata-rata respon mahasiswa sebesar 2,52 yang menunjukkan mahasiswa memberikan respon positif terhadap modul geometri berbasis reciprocal teaching. Maka secara keseluruhan dapat disimpulkan bahwa modul geometri berbasis reciprocal teaching mampu meningkatkan kemampuan komunikasi matematis mahasiswa calon guru.
\end{abstract}

Kata kunci: Modul, Reciprocal teaching, Komunikasi matematis

\section{PENDAHULUAN}

Pendidikan di Indonesia harus selalu berbenah diri dalam semua bidang yang terkait langsung dengan masalah pendidikan formal, hal ini tertera dalam undang-undang nomor 20 tentang sistem pendidikan di Indonesia dan undang-undang guru dan dosen no 14 tahun 2005. Hal ini menyebabkan pemerintah berusaha untuk meningkatkan kualitas pendidikan khususnya pembelajaran matematika. Berbagai model pembelajaran diterapkan agar mampu meningkatkan penguasaan matematika peserta didik. Menurut (Anggani, 2000) agar tujuan pembelajaran dapat tercapai dan proses belajar mengajar yang tercipta tidak membosankan, tenaga pengajar dapat menggunakan media pembelajaran secara tepat.

Media pembelajaran adalah suatu alat bantu ataupun sarana bagi pendidik untuk menyampaikan suatu informasi maupun pesan sehingga materi yang diberikan akan lebih menarik dan dapat dipahami oleh siswa (M.Nur, 2016). Adapun tujuan dari media pembelajaran ini adalah suatu alat yang digunakan dalam menyiapkan bahan ajar salah satunya adalah modul dalam suatu proses pembelajaran sehingga lebih efektif, praktis, serta efisien. Fungsi dari modul untuk mahasiswa adalah media pembelajaran dimana membantu dalam proses belajar secara mandiri tanpa ada batasan waktu 
ataupun harus bertemu secara langsung dengan dosen sehingga sebagai pemandu sudut pandang dari mahasiswa dalam memahami dan memberikan gambaran yang jelas dari suatu materi. (Festiana et al., 2014) mengatakan pembelajaran menggunakan modul mampu memberikan konstribusi secara signifikan dalam meningkatkan hasil belajar mahasiswa.

Pembelajaran yang efektif ditandai dengan mahasiswa mampu memahami materi yang diberikan. Proses dalam pembelajaran sering melibatkan dengan membaca teks. Membaca teks merupakan salah satu dari berbagai unsur komunikasi matematis. Oleh sebab itu mahasiswa harus mempunyai ketrampilan ataupun kemampuan dalam membaca teks. Meningkatkan komunikasi matematis mahasiswa merupakan sesuatu hal yang penting dilakukan karena matematika adalah suatu alat komunikasi dalam artian matematika merupakan bahasa simbol dimana digunakan untuk mengubah suatu pernyataan dalam bentuk simbol, rumus, ataupun gambar. Romberg dan Chair (Sumarmo, 2005) menyatakan bahwa komunikasi matematis adalah hubungan antara benda nyata, gambar ataupun diagram ke dalam bentuk ide matematika; kemudian ide itu akan dijelaskan, selain itu relasi dan situasi matematis disajikan secara tulisan atau lisan melalui benda nyata, grafik, gambar, maupun aljabar; peristiwa yang terjadi dalam kehidupan sehari-hari dinyatakan dalam simbol ataupun bahasa matematika; mendengarkan, berdiskusi, dan menulis tentang matematika; mampu membaca dengan pemahaman suatu presentasi matematika tertulis, menyusun argumen, membuat konjektur, merumuskan definisi dan generalisasi; mampu menjelaskan dan kemudian membuat pertanyaan mengenai matematika yang telah dipelajari. Berdasarkan pendapat diatas maka dapat disimpulkan bahwa kemampuan matematis dilihat melalui dua hal yaitu kemampuan mahasiswa dalam menggunakan matematika untuk alat komunikasi atau bahasa matematika dan kemampuan dari mahasiswa dalam mengkomunikasikan matematika yang telah dipelajari. Jadi dapat dikatakan komunikasi lisan dan tulisan merupakan bagian dari komunikasi matematis.

Kemampuan mahasiswa dalam komunikasi matematis perlu dioptimalkan untuk memperoleh hasil yang diharapkan. Untuk itu model pembelajaran reciprocal teaching atau pembelajaran terbalik menjadi suatu alternatif model pembelajaran dimana diharapkan melalui model pembelajaran reciprocal teaching ini mampu mengembangkan kemampuan komunikasi matematis dan pemahaman matematis mahasiswa. (Cai et al., 1996) menyatakan bahwa pemahaman matematis diperlukan dalam mengembangkan kemampuan matematis dimana pemahaman yang dimaksud adalah pemahaman terhadap konsep maupun strategi dalam penyelesaian. Selain itu (Rahman, 2004) dalam penelitiannya menyatakan bahwa penggunaan model pembelajaran reciprocal teaching mampu meningkatkan pemahaman dan kemampuan generalisasdi matematis pada siswa SMA. (Rachmayani, 2014) meneliti kemampuan komunikasi matematis siswa antara model pembelajaran reciprocal teaching melalui pendekatan metakognitif dengan pembelajaran biasa menunjukkan bahwa kemampuan komunikasi matematis siswa meningkat setelah diberikan model pembelajaran reciprocal teaching melalui pendekatan metakognitif. 
Geometri merupakan konsep yang abstrak bagi mahasiswa calon guru. Berdasarkan hasil pengamatan peneliti terdapat beberapa permasalahan yang terkait mata kuliah geometri di IKIP Budi Utomo Malang adalah mahasiswa masih kesulitan dalam memecahkan masalah, cara berpikir mahasiswa yang masih bersifat teoritis, serta mahasiswa sulit memahami materi yang diberikan. Perlu adanya perbaikan-perbaikan baik dari segi kualitas pembelajaran ataupun segi kualitas tenaga pengajarnya. Pada penelitian ini peneliti akan mengembangkan bahan ajar dalam bentuk modul berbasis reciprocal teaching untuk meningkatkan kualitas pembelajaran geometri.

\section{METODE}

Pengembangan modul ini menggunakan model pengembangan Plomp. Model pengembangan Plomp (dalam hobri, 2010) mengatakan bahwa terdiri dari lima tahapan, antara lain sebagai berikut: 1) Tahap investigasi dimana didalamnya meliputi analisis awal, analisis terhadap mahasiswa, analisis materi, serta penyusunan tujuan dari pembelajaran; 2) Tahap desain yaitu tahap dimana dihasilkan sebuah rancangan modul; 3) Tahap konstruksi atau realisasi adalah rancangan modul yang akan dikembangkan kemudian direalisasikan sehingga menghasilkan modul mahasiswa; 4) Tahap tes, evaluasi serta revisi yaitu tahapan diman modul akan divalidari oleh ahli dan dilakukan uji lapangan. Pada penelitian ini hanya mengadopsi sampai pada tahap empat karena penggunaannya terbatas pada mahasiswa calon guru pendidikan matematika IKIP Budi Utomo Malang. Subyek penelitian ini adalah mahasiswa calon guru pendidikan matematika IKIP Budi Utomo Malang yang tengah mengampu mata kuliah geometri.

Analisis awal

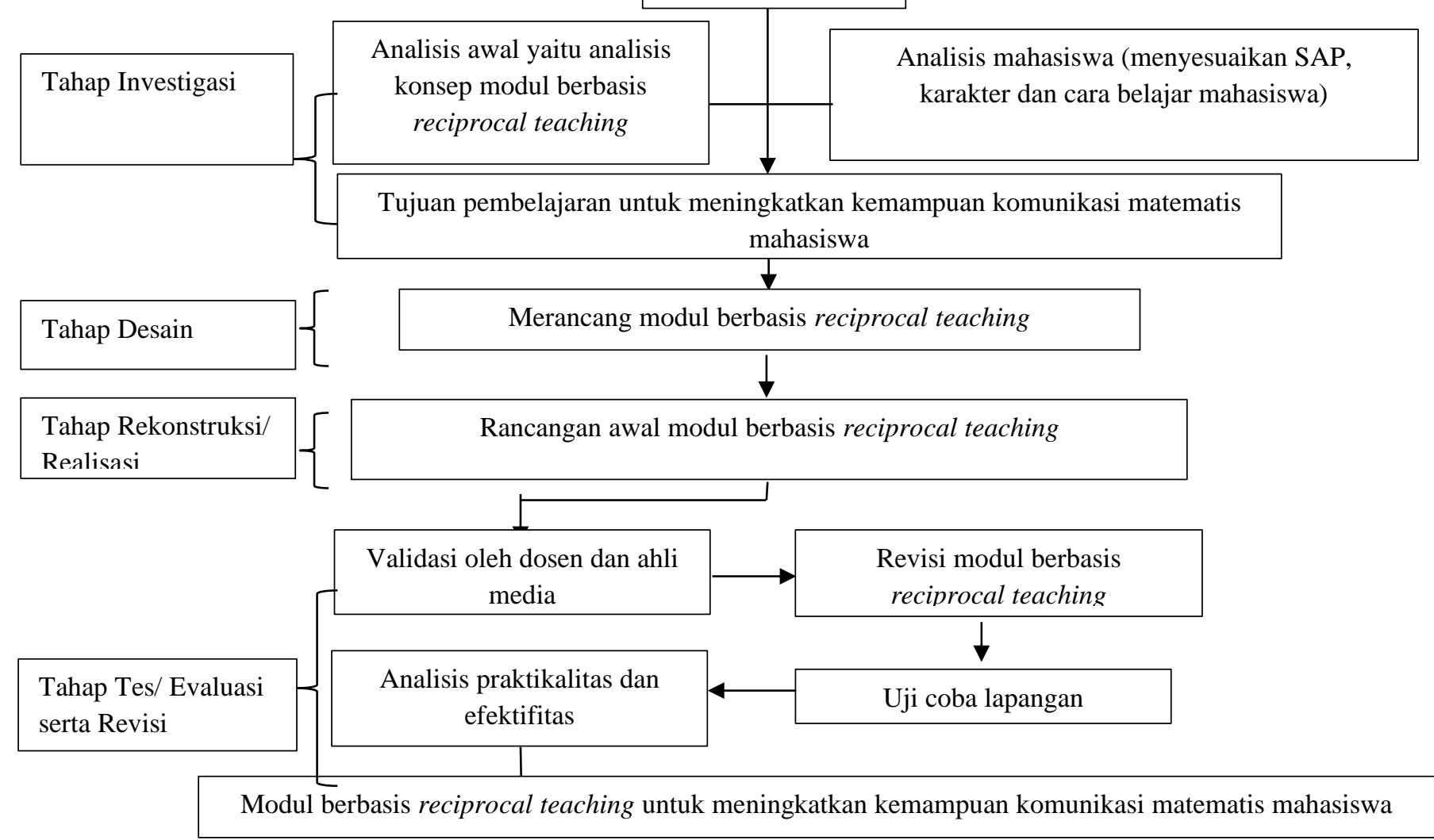

Gambar 1. Prosedur Penelitian Dengan Model Pengembangan Plomp. 
Modul yang dikembangkan adalah modul geometri berbasis reciprocal teaching yang bertujuan untuk meningkatkan kemampuan komunikasi matematis pada mahasiswa calon guru. Modul yang dikembangkan disusun secara sistematik dimana terdiri dari petunjuk penggunaan, materi yang diberikan, soal latihan, dan kunci jawaban. (Wulandari \& Lepiyanto, 2016) mengatakan bahwa modul merupakan bahan ajar yang tersusun secara sistematis dan isinya mencangkup materi, metode serta evaluasi sehingga dapat digunakan mandiri. Modul yang dikembangkan ini akan divalidasi oleh dosen dan ahli media. (Parta, 2009) mengatakan kriteria kevalidan terdiri dari empat skala penilaian yaitu tidak valid dengan skor nilai 1 , kurang valid dengan skor nilai 2 , valid dengan skor nilai 3 , dan sangat valid dengan skor nilai 4 . Setelah dinilai secara diskriptif dan dihitung rata-rata skor setiap aspek maka ditentukan klasifikasi kriteria kevalidannya seperti tabel dibawah ini.

\section{Tabel 1.}

\section{Klasifikasi Kriteria Penilaian Validitas}

\begin{tabular}{|c|l|c|}
\hline No. & Nilai & Kriteria kevalidan \\
\hline 1 & $\bar{x} \geq 3$ & Valid \\
\hline 2 & $2 \leq \bar{x}<3$ & Cukup valid \\
\hline 3 & $\bar{x}<2$ & Tidak valid \\
\hline
\end{tabular}

Uji praktikalitas dianalisis secara deskriptif menggunakan lembar keterlaksanaan modul geometri berbasis reciprocal teaching. Prosedur dalam menentukan praktikalitas adalah sebagai berikut: 1) Merekap nilai masing-masing aspek, 2) Menghitung rata-rata secara keseluruhan, dan 3) Membuat kesimpulan. (Parta, 2009) menyebutkan perhitungan praktikalitas menggunakan empat skala yaitu tidak sesuai dengan nilai 1 , cukup sesuai dengan nilai 2 , sesuai dengan nilai 3 , dan sangat sesuai dengan nilai 4. Kemudian rentang nilai antara 1 sampai 4 dibuat dalam 3 subinterval yaitu $1 \leq \bar{x}<2,2 \leq \bar{x}<3$, dan $3 \leq \bar{x} \leq 4$. Maka berdasarkan acuan tersebut dikembangkan sesuai dengan kebutuhan seperti terlihat dalam tabel berikut.

\section{Tabel 2.}

Klasifikasi Kriteria Penilaian Praktikalitas

\begin{tabular}{|c|l|c|}
\hline No & Nilai & Kriteria praktikalitas \\
\hline 1 & $\bar{x} \geq 3$ & Praktis \\
\hline 2 & $2 \leq \bar{x}<3$ & Cukup Praktis \\
\hline 3 & $\bar{x}<2$ & Tidak Praktis \\
\hline
\end{tabular}

Efektivitas modul geometri berbasis reciprocal teaching dianalisis secara deskriptif. Keefektifan ini adalah untuk mengetahui informasi bagaimana kemampuan matematis mahasiswa sebelum adanya perkuliahan atau pretest dan setelah perkuliahan menggunakan modul geometri berbasis reciprocal teaching atau posttest. Tes pretest dan posttest ini berbentuk pertanyaan tes esai dimana soal yang disusun disertai dengan kunci jawaban dan aturan penskoran dari setiap jawaban. Efektivitas modul mengacu pada kriteria efektivitas menurut (Kemp, J.E., Morisson, G.R., dan Ross, 1994) yang disesuaikan dengan penelitian ini. Kriteria efektivitas modul geometri berbasis reciprocal teaching 
antara lain: 1) Rata-rata kemampuan matematis mahasiswa masuk dalam kategori sedang atau tinggi dimana perhitungannya menggunakan rumus gain ternomalisasi dari (Hake, 1999); 2) 50\% atau lebih mahasiswa memberikan respon positif terhadap modul geometri berbasis reciprocal teaching. Menurut (Syarifuddin, 2011) menyatakan dalam menyikapi situasi yang baru maka sikap yang muncul adalah menerima (memberikan respon positif) atau menolak (memberikan respon negatif). Sehingga rentang nilai dibagi dua yaitu $1 \leq \bar{x}<2$ dan $2 \leq \bar{x}<3$.

\section{Tabel 3.}

\section{Klasifikasi Kriteria Penilaian Respon Mahasiswa}

\begin{tabular}{|c|l|c|}
\hline No & Nilai & Kriteria Respon \\
\hline 1 & $1 \leq \bar{x}<2$ & Negatif \\
\hline 2 & $2 \leq \bar{x}<3$ & Positif \\
\hline
\end{tabular}

HASIL

Berdasarkan rancangan modul geometri berbasis reciprocal teaching yang dikembangkan maka harus diadakan uji validitas, praktikalitas dan efektivitas dari produk yang dikembangkan.

\section{Validitas}

Pengujian validitas modul geometri berbasis reciprocal teaching dilakukan oleh dosen dan ahli media. Aspek yang dinilai mencangkup dari kesesuaian isi dari materi yang diberikan, model pembelajarannya serta tampilan dari modul yang dikembangkan.

\section{Tabel 4.}

Hasil Rekapitulasi Validator

\begin{tabular}{|c|c|c|c|c|c|}
\hline \multirow[t]{2}{*}{ Aspek } & \multirow[t]{2}{*}{ Indikator } & \multicolumn{2}{|c|}{$\begin{array}{l}\text { Validator } \\
\text { Ke- }\end{array}$} & \multirow[t]{2}{*}{$\overline{x_{\boldsymbol{\imath}}}$} & \multirow[t]{2}{*}{$\bar{x}$} \\
\hline & & 1 & 2 & & \\
\hline \multirow{4}{*}{$\begin{array}{l}\text { Kesesuaian } \\
\text { Isi }\end{array}$} & 1. Kesesuaian materi geometri & 4 & 3 & 3,5 & 3,4 \\
\hline & $\begin{array}{l}\text { 2. Menampilkan masalah yang sesuai } \\
\text { dengan model pembelajaran reciprocal } \\
\text { teaching }\end{array}$ & 4 & 4 & 4 & \\
\hline & $\begin{array}{l}\text { 3. Masalah yang ditampilkan pada modul } \\
\text { memberikan rangsangan untuk } \\
\text { mahasiswa dalam mengidentifikasi } \\
\text { konsep geometri }\end{array}$ & 3 & 3 & 3 & \\
\hline & $\begin{array}{l}\text { 4. Modul mampu memberikan bimbingan } \\
\text { mahasiswa untuk meningkatkan } \\
\text { komunikasi matematis mahasiswa }\end{array}$ & 3 & 4 & 3,5 & \\
\hline \multirow{6}{*}{$\begin{array}{l}\text { Kesesuaian } \\
\text { Tampilan }\end{array}$} & 5. Modul mudah dipelajari & 4 & 4 & 4 & \\
\hline & $\begin{array}{l}\text { 6. Modul dilengkapi dengan petunjuk } \\
\text { penggunaan dan kunci jawaban }\end{array}$ & 3 & 3 & 3 & \\
\hline & $\begin{array}{l}\text { 7. Kesesuaian ukuran dan tata letak gambar } \\
\text { serta tulisan }\end{array}$ & 3 & 3 & 3 & \\
\hline & $\begin{array}{l}\text { 8. Kesesuaian konbinasi warna, tulisan, dan } \\
\text { gambar }\end{array}$ & 4 & 3 & 3,5 & \\
\hline & 9. Kalimat yang digunakan jelas & 3 & 3 & 3 & \\
\hline & 10. Penampilan modul menarik perhatian & 3 & 4 & 3,5 & \\
\hline
\end{tabular}


Hasil dari rekapitulasi validator adalah 3,4 sehingga masuk kategori valid jadi modul geometri berbasis reciprocal teaching layak untuk digunakan.

\section{Praktikalitas}

Praktikalitas dilihat dari beberapa segi yaitu mudah atau tidak modul yang dikembangkan, keefektifan dari segi waktu dalam pembelajaran, serta manfaat yang diperoleh dengan menggunakan modul ini.

\section{Tabel 5.}

Hasil Rekapitulasi Observer

\begin{tabular}{|c|c|c|c|c|c|}
\hline \multirow{2}{*}{ No } & \multirow{2}{*}{ Indikator } & \multicolumn{2}{|c|}{ Observer Ke- } & \multirow{2}{*}{$\overline{x_{\boldsymbol{\imath}}}$} & \multirow{2}{*}{$\overline{\boldsymbol{x}}$} \\
\hline & & 1 & 2 & & \\
\hline 1 & $\begin{array}{l}\text { Mahasiswa mudah dalam menggunakan modul } \\
\text { geometri berbasis reciprocal teaching }\end{array}$ & 3 & 4 & 3,5 & 3,0 \\
\hline 2 & $\begin{array}{l}\text { Mahasiswa melakukan aktivitas yang diminta menurut } \\
\text { tahapan yang terdapat pada modul geometri berbasis } \\
\text { reciprocal teaching }\end{array}$ & 3 & 3 & 3 & \\
\hline 3 & $\begin{array}{l}\text { Mahasiswa mampu menyimpulkan konsep geometri } \\
\text { dari aktivitas yang dilakukan }\end{array}$ & 4 & 3 & 3,5 & \\
\hline 4 & $\begin{array}{l}\text { Bahasa yang dipakai dalam modul geometri berbasis } \\
\text { reciprocal teaching komunikatif dan mudah dipahami } \\
\text { mahasiswa }\end{array}$ & 3 & 3 & 3 & \\
\hline 5 & $\begin{array}{l}\text { Latihan soal dalam modul geometri berbasis reciprocal } \\
\text { teaching sulit dikerjakan mahasiswa }\end{array}$ & 2 & 2 & 2 & \\
\hline 6 & $\begin{array}{l}\text { Secara menyeluruhmodul modul geometri berbasis } \\
\text { reciprocal teaching dapat digunakan dalam proses } \\
\text { pembelajaran }\end{array}$ & 3 & 3 & 3 & \\
\hline
\end{tabular}

Secara keseluruhan maka rata-rata praktikalitas sebesar 3,0 sehingga masuk dalam kategori praktis digunakan. Maka dapat dikatakan modul yang dikembangkan sesuai dengan yang diharapkan dimana modul geometri berbasis reciprocal teaching bersifat sederhana yaitu mahasiswa tidak membutuhkan media yang sulit untuk mempelajarinya dan modul yang dikembangkan bersifat lengkap karena berisi materi, petunjuk pengerjaan, latihan soal, kunci jawaban, dan skor yang diperoleh.

\section{Efektivitas}

Kriteria efektivitas modul geometri berbasis reciprocal teaching untuk meningkatkan kemampuan komunikasi matematis mahasiswa calon guru dilihat dari rata-rata kemampuan matematis mahasiswa dan respon mahasiswa terhadap modul geometri berbasis reciprocal teaching.

\section{Hasil Tes Kemampuan Komunikasi Matematis Mahasiswa}

Hasil tes kemampuan komunikasi matematis mahasiswa selama pretest dan setelah posttest menggunakan modul geometri berbasis reciprocal teaching adalah sebagai berikut.

Tabel 6.

Hasil Kemampuan Komunikasi Matematis Mahasiswa.

\begin{tabular}{|l|c|}
\hline & Rata-rata \\
\hline Pretest & 64,72 \\
\hline Posttest & 76,80 \\
\hline Gain & 12,08 \\
\hline Gain skor ternormalisasi & 0,52 \\
\hline
\end{tabular}


Tabel 6. menyatakan bahwa hasil kemampuan matematis mahasiswa pada materi geometri sebelum adanya pembelajaran rata-ratanya sebesar 64,72 dimana nilai tersebut tergolong dalam kategori rendah dengan aturan nilai maksimum yang diperoleh adalah 100. Kemudian dilakukan tes setelah adanya pembelajaran menggunakan modul geometri berbasis reciprocal teaching dan terjadi peningkatan kemampuan matematis mahasiswa rata-ratanya sebesar 76,80. Dapat dilihat peningkatan kemampuan matematis mahasiswa sebesar 12,08. Kemudian menggunakan gain skor diperoleh kemampuan matematis mahasiswa meningkat 0,52 dimana masuk dalam kategori sedang.

\section{Data Hasil Respon Mahasiswa terhadap Modul Geometri}

Data hasil respon mahasiswa terhadap modul geometri berbasis reciprocal teaching dapat dilihat pada tabel dibawah ini.

\section{Tabel 7.}

Hasil Respon mahasiswa dengan modul geometri berbasis reciprocal teaching

\begin{tabular}{|c|l|c|}
\hline No & \multicolumn{1}{|c|}{ Aspek yang Dinilai } & Rata-rata \\
\hline 1 & $\begin{array}{l}\text { Saya tertarik dan merasa ingin tahu ketika belajar menggunakan modul } \\
\text { geometri berbasis reciprocal teaching }\end{array}$ & 2,75 \\
\hline 2 & $\begin{array}{l}\text { Aktivitas dalam modul geometri berbasis reciprocal teaching } \\
\text { memberikan kesempatan dalam menentukan konsep geometri }\end{array}$ & 2,90 \\
\hline 3 & $\begin{array}{l}\text { Petunjuk penggunaan modul geometri berbasis reciprocal teaching } \\
\text { memberikan saya kemudahan dalam pembelajaran }\end{array}$ & 2,10 \\
\hline 4 & $\begin{array}{l}\text { Modul geometri berbasis reciprocal teaching membantu saya untuk } \\
\text { mengecek apakah jawaban saya benar atau salah }\end{array}$ & 2,65 \\
\hline 5 & $\begin{array}{l}\text { Aktivitas dalam modul geometri berbasis reciprocal teaching } \\
\text { membantu saya untuk berdiskusi dan berinteraksi dengan rekan }\end{array}$ & 2,15 \\
\hline 6 & $\begin{array}{l}\text { Secara keseluruhan saya puas terhadap isi, kualitas tampilan serta } \\
\text { gambar di dalam modul }\end{array}$ & 2,60 \\
\hline Total & \multicolumn{2}{|l}{2,52} \\
\hline
\end{tabular}

Berdasarkan tabel 7 diperoleh rata-rata keseluruhan adalah 2,52 sehingga masuk dalam kategori mahasiswa memberikan respon positif. Menggunakan modul geometri berbasis reciprocal teaching membuat mahasiswa lebih mudah dalam memahami materi geometri. Secara keseluruhan mahasiswa juga merapa puas dengan isi dan tampilan dalam modul. Sesuai dengan pendapat (Harta et al., 2014) bahwa pembelajaran menggunakan modul mampu meningkatkan aktivitas dan minat siswa dalam pembelajaran.

Hasil deskripsi tentang penggunaan modul geometri berbasis reciprocal teaching menunjukkan bahwa kemampuan komunikasi matematis mahasiswa meningkat. Hal ini dilihat dari dua aspek antara lain: 1) Rata-rata kemampuan matematis mahasiswa sebesar 0,52 dimana masuk dalam kategori sedang; 2) Rata-rata respon mahasiswa sebesar 2,52 yang menunjukkan mahasiswa memberikan respon positif terhadap modul geometri berbasis reciprocal teaching. Sesuai dengan pernyataan (Rahman, 2004) yaitu penggunaan model pembelajaran reciprocal teaching mampu meningkatkan kemampuan generalisasi dan pemahaman matematis siswa. (Ketong et al., 2018) juga mengatakan bahwa reciprocal teaching 
efektif untuk meningkatkan kemampuan membaca dan pemahaman siswa dalam menyelesaikan masalah.

\section{KESIMPULAN}

Berdasarkan deskripsi diatas maka dapat disimpulkan sebagai berikut: 1) dihasilkan modul geometri berbasis reciprocal teaching untuk mahasiswa calon guru; 2) hasil validasi modul diperoleh rata-rata secara keseluruhan sebesar 3,4 dimana modul yang dikembangkan masuk dalam kategori valid atau layak digunakan; 3) hasil rata-rata praktikalitas sebesar 3,0 dimana masuk dalam kategori praktis digunakan; 4) hasil keefektivan dinilai dari hasil kemampuan komunikasi matematis mahasiswa calon guru yaitu meningkat sebesar 0,52 dimana masuk dalam kategori sedang, kemudian rata-rata respon mahasiswa sebesar 2,52 yang menunjukkan mahasiswa memberikan respon positif terhadap modul geometri berbasis reciprocal teaching. Maka secara keseluruhan modul geometri berbasis reciprocal teaching mampu meningkatkan kemampuan komunikasi matematis mahasiswa calon guru.

\section{DAFTAR PUSTAKA}

Anggani, S. (2000). Sumber Belajar Dan Alat Permainan. Jakarta: Grasindo.

Cai, J., Jakabcsin, M. S., \& Lane, S. (1996). Assessing Students' Mathematical Communication. School Science and Mathematics, 96(5), 238-246. https://doi.org/10.1111/j.1949-8594.1996.tb10235.x

Festiana, I., -, S., \& -, S. (2014). Pengembangan Modul Fisika Berbasis Masalah Pada Materi Listrik Dinamis Untuk Meningkatkan Kemampuan Berpikir Kreatif Siswa Sma. Inkuiri, 3(3), 36-47. https://doi.org/10.20961/inkuiri.v3i2.9682

Hake, R. R. (1999). Analyzing change/gain scores. Unpublished.[Online] URL: Http://Www. Physics. Indiana. $\quad E d u \wedge \sim \quad$ Sdi/AnalyzingChange-Gain. $\quad P d f, \quad$ 16(7), 1073-1080. http://www.ncbi.nlm.nih.gov/pubmed/22025883\%5Cnhttp://scholar.google.com/scholar?hl=en\& btnG=Search\&q=intitle:ANALYZING+CHANGE/GAIN+SCORES\#0\%5Cnhttp://scholar.googl e.com/scholar?hl=en\&btnG=Search\&q=intitle:Analyzing+change/gain+scores\#0

Harta, I., Tenggara, S., \& Kartasura, P. (2014). Pengembangan Modul Pembelajaran untuk Meningkatkan Pemahaman Konsep dan Minat SMP. Pythagoras: Jurnal Pendidikan Matematika, 9(2), 161-174. https://doi.org/10.21831/pg.v9i2.9077

hobri, H. (2010). Metodologi Penelitian Pengembangan (Aplikasi Pada Penelitian Pendidikan Matematika). Pena salsabila.

Kemp, J.E., Morisson, G.R., dan Ross, S. . (1994). Designing Effective Instruction. New York: Macmillan College Publishing, Inc.

Ketong, S., Burhanuddin, B., \& Asri, W. K. (2018). Keefektifan Model Pembelajaran Reciprocal Teaching Dalam Kemampuan Membaca Memahami Siswa Kelas Xi Ipa Sma Negeri 11 Makassar. Eralingua: Jurnal Pendidikan Bahasa Asing Dan Sastra, 2(1), 45-54. https://doi.org/10.26858/eralingua.v2i1.5629 
Pengembangan Modul Geometri Berbasis Reciprocal Teaching Untuk Meningkatkan Kemampuan Komunikasi Matematis

M.Nur, I. (2016). Pemanfaatan Program Geogebra Dalam Pembelajaran Matematika. Jurnal Matematika Dan Pendidikan Matematika, 5(1), 79-89.

Parta, I. N. (2009). Pengembangan Model Pembelajaran Inquiry untuk Penghalusan Pengetahuan Matematika Mahasiswa Calon Guru Melalui Pengajuan Pertanyaan. Malang: Program Pasca Sarjana Universitas Negeri Malang.

Rachmayani, D. (2014). Penerapan Pembelajaran Reciprocal Teaching Untuk Meningkatkan Kemampuan Komunikasi Matematis Dan Kemandirian Belajar Matematika Siswa. Jurnal Pendidikan Unsika, 2(1), 13-23. https://journal.unsika.ac.id/index.php/judika/article/view/118

Rahman, A. (2004). Kemampuan Pemahaman dan Kemampuan Generalisasi matematik siswa SMA dengan Menggunakan Model Pembelajaran Berbalik. Bandung: Program Pascasarjana UPI.

Sumarmo, U. (2005). Pengembangan Berfikir Matematis Tingkat Tinggi Siswa SLTP dan SMU serta Mahasiswa Strata Satu (S1) melalui Berbagai Pendekatan Pembelajaran. Laporan Penelitian tidak Diterbitkan. Bandung: Lemlit UPI.

Syarifuddin. (2011). Pengembangan Buku Siswa SMP Kelas VIII Dengan Materi Prisma dan Limas yang Berpijak Pada masalah Konstekstual, Penggunaan Model, dan Penemuan Terbimbing. Malang: Program Pasca Sarjana Universitas Negeri Malang.

Wulandari, H., \& Lepiyanto, A. (2016). Pengembangan Modul Pembelajaran Biologi Berorientasi Siklus Belajar Untuk Siswa Kelas Xi Sma Teladan 1 Metro. BIOEDUKASI (Jurnal Pendidikan Biologi), 7(2), 129-132. https://doi.org/10.24127/bioedukasi.v7i2.614 